Supplement of Hydrol. Earth Syst. Sci., 25, 3281-3299, 2021

https://doi.org/10.5194/hess-25-3281-2021-supplement

(C) Author(s) 2021. CC BY 4.0 License.

(c) (i)

Supplement of

\title{
Water resources management and dynamic changes in water politics in the transboundary river basins of Central Asia
}

Xuanxuan Wang et al.

Correspondence to: Zhi Li (liz@ms.xjb.ac.cn)

The copyright of individual parts of the supplement might differ from the article licence. 

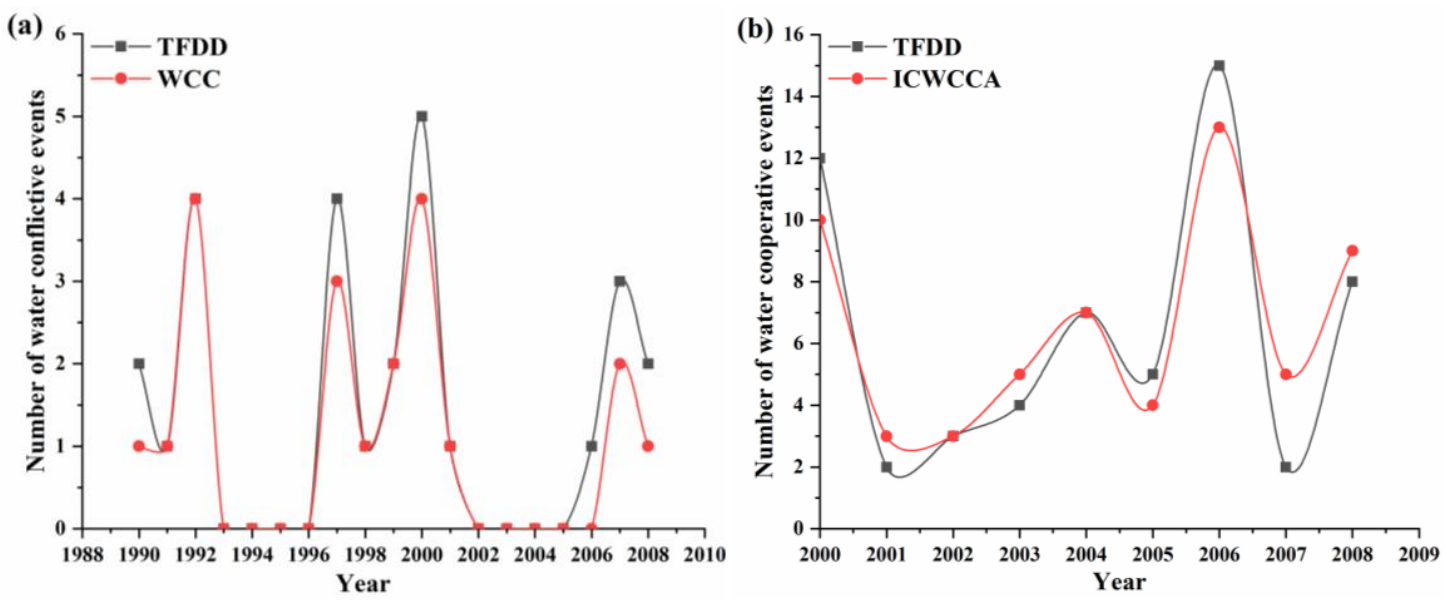

Figure S1: Comparison of the number of water conflictive events in the TFDD and WCC datasets (a) and the number of water cooperative events in the TFDD and ICWCCA datasets (b). 